CHRONIC OBSTRUCTIVE PULMONARY DISEASE

\title{
Regular physical activity reduces hospital admission and mortality in chronic obstructive pulmonary disease: a population based cohort study
}

\author{
J Garcia-Aymerich, P Lange, M Benet, P Schnohr, J M Antó
}

See end of article for authors' affiliations

\section{..................... \\ Correspondence to: Dr J Garcia-Aymerich, Respiratory and Environmental Health Research Unit, Institut Municipal d'Investigació Mèdica (IMIM), Doctor Aiguader 80, E-08003- Barcelona, Spain; igarcia@imim.es}

Received 7 February 2006 Accepted 10 May 2006 Published Online First 31 May 2006

\begin{abstract}
Background: Information about the influence of regular physical activity on the course of chronic obstructive pulmonary disease (COPD) is scarce. A study was undertaken to examine the association between regular physical activity and both hospital admissions for COPD and all-cause and specific mortality in COPD subjects.

Methods: From a population-based sample recruited in Copenhagen in 1981-3 and 1991-4, 2386 individuals with COPD (according to lung function tests) were identified and followed until 2000. Selfreported regular physical activity at baseline was classified into four categories (very low, low, moderate, and high). Dates and causes of hospital admissions and mortality were obtained from Danish registers. Adjusted associations between physical activity and hospital admissions for COPD and mortality were obtained using negative binomial and Cox regression models, respectively.

Results: After adjustment for relevant confounders, subjects reporting low, moderate or high physical activity had a lower risk of hospital admission for COPD during the follow up period than those who reported very low physical activity (incidence rate ratio $0.72,95 \%$ confidence interval (Cl) 0.53 to 0.97 ). Low, moderate and high levels of regular physical activity were associated with an adjusted lower risk of all-cause mortality (hazard ratio (HR) $0.76,95 \% \mathrm{Cl} 0.65$ to 0.90 ) and respiratory mortality (HR $0.70,95 \%$ $\mathrm{Cl} 0.48$ to 1.02). No effect modification was found for sex, age group, COPD severity, or a background of ischaemic heart disease.

Conclusions: Subjects with COPD who perform some level of regular physical activity have a lower risk of both COPD admissions and mortality. The recommendation that COPD patients be encouraged to maintain or increase their levels of regular physical activity should be considered in future COPD guidelines, since it is likely to result in a relevant public health benefit.
\end{abstract} cycling could be associated with an improvement in the course of COPD is worthy of further investigation. The lack of research on the influence of regular physical activity on the natural history of COPD is in contrast to that existing for other chronic diseases such as type 2 diabetes ${ }^{10}$ or cancer $^{11} 12$ in which higher levels of physical activity (equivalent to walking 3-5 hours/week) have even been related to a reduced risk of death from the chronic disease in question. ${ }^{13}$ In the present study we examined the association between regular physical activity and both hospital admission due to COPD and all-cause and specific mortality in a large prospective cohort study of COPD subjects sampled from the general population in Copenhagen and followed up for a mean of 12.0 years. The study is part of the Copenhagen City Heart Study (CCHS) which has already provided relevant information about the course of COPD. ${ }^{14-16}$

\section{METHODS}

\section{Study design and population}

The CCHS involves the study of an ongoing prospective cohort of adults recruited from the general population, with repeated examinations every 5-10 years. A random age stratified sample of the general population aged 20 years or more was drawn from the Copenhagen Population Register as of 1 January 1976 and a first examination $(n=14223)$ took place in 1976-8. At the second examination 5 years later (1981-3), the cohort was supplemented with a new sample of subjects aged 20-24 years (total $n=12698$ ). In the third examination (1991-4) the sample was supplemented with

Abbreviations: COPD, chronic obstructive pulmonary disease; $\mathrm{FEV}_{1}$, forced expiratory volume in 1 second; FVC, forced vital capacity 
20-49 year old subjects (total $\mathrm{n}=10$ 135). ${ }^{17}{ }^{18}$ The institutional review board and Danish regional ethics committees approved the research protocol. Participants gave written informed consent.

Since the first CCHS examination provided limited information about regular physical activity, for the present study we selected all participants included in the second examination (1981-3) together with the complementary sample of the third CCHS examination (1991-4). Of these 15563 subjects, 2386 met the criteria for COPD and were included in the present analysis. COPD was defined on the basis of lung function test results including forced expiratory volume in 1 second $\left(\mathrm{FEV}_{1}\right)$ and forced vital capacity (FVC) as the presence of airway obstruction $\left(\mathrm{FEV}_{1} / \mathrm{FVC} \leqslant 70 \%\right)$ and classified according to the degree of airway obstruction: ${ }^{34}$ mild $\left(\mathrm{FEV}_{1} \geqslant 80 \%\right)$, moderate $\left(\mathrm{FEV}_{1}<80 \%\right.$ and $\left.\geqslant 50 \%\right)$, severe $\left(\mathrm{FEV}_{1}<50 \%\right.$ and $\left.\geqslant 30 \%\right)$, and very severe $\left(\mathrm{FEV}_{1}\right.$ $<30 \%)$. Subjects who, in addition to COPD, reported having suffered asthma $(n=268)$ were initially included, although a later sensitivity analysis excluded this group. The date of participation in the second CCHS examination or-in those newly recruited from the third CCHS examination, the date of participation in the third CCHS examination-was considered the start of the follow up period. Subjects were followed up either to the time of death or to 28 December 2000 , with a mean of 12 years follow up (range 0.5-20 years) providing a total of 28747 person years.

\section{Measurements}

Identical methods were applied in the second and third CCHS examinations and have been previously described in detail. ${ }^{17}{ }^{18}$ For the present analysis only the measurements of physical activity and other independent variables obtained at the start of the follow up period were used. A selfadministered questionnaire on regular physical activity over the previous 12 months, current smoking and alcohol consumption, socioeconomic factors (sex, age, education, marital status, cohabitation, income), current symptoms (dyspnoea, ${ }^{19}$ sputum, chest pain, leg pain and intermittent claudication), a diagnosis of co-morbidity at any time (asthma, ischaemic heart disease, myocardial infarction, stroke, diabetes), and health service use over the previous 12 months was completed and checked by the CCHS staff. Blood pressure, plasma cholesterol, glucose concentrations, and body mass index were also measured. Clinical records were reviewed to obtain information about co-morbidity.

Physical activity was measured using a questionnaire originally developed by Saltin and Grimby ${ }^{20}$ which discriminates between sedentary persons and their more active counterparts with respect to maximal oxygen uptake, ${ }^{21}$ and has been widely used to describe the effects of physical activity on health outcomes in similar types of populations. ${ }^{22}{ }^{23}$ Physical activity variables included physical activity at work, physical activity during leisure time, jogging, cycling in winter, and cycling in summer. The level of physical activity was classified as previously reported: ${ }^{24}$ (1) low: engaging in light physical activity such as walking or biking for less than 2 hours/week; (2) moderate: engaging in light physical activity for 2-4 hours/week; and (3) high: engaging in light physical activity for more than 4 hours/week or in more vigorous activity for any frequency. As we have previously reported differences in the risk of hospital admission for COPD between subjects who reported low levels of physical activity and those who reported very low physical activity, ${ }^{6}$ in the present analysis the "low" category was split into very low physical activity (corresponding to those who reported mainly sitting during work, no activity during leisure time, and no jogging or cycling) and low levels of physical activity for the remaining subjects.
Lung function parameters ( $\mathrm{FEV}_{1}$ and FVC) were measured at the second CCHS examination with an electronic spirometer (Model N403; Monaghan, Littleton, CO, USA) which was calibrated daily with a 1 litre syringe and weekly against a water sealed Godard spirometer. At the third examination a dry wedge spirometer (Vitalograph, Maidenhead, UK), calibrated daily with a l litre syringe, was used. At each examination three sets of values were obtained and at least two measurements differing by less than $5 \%$ had to be produced. The highest measurements of $\mathrm{FEV}_{1}$ and FVC were used in the analyses as absolute values and as percentage of predicted values, using internally derived reference values based on a subsample of healthy never smokers. ${ }^{25}$ Information about hospital admissions (dates and diagnoses on discharge) both before the start and during follow up was obtained from the National Patient Register which covers all Danish hospitals and is administered by the National Board of Health. COPD admission was defined as any admission classified as ICD-8 codes 490-492 or ICD-10 codes J40-J44 for the main diagnosis. Data on deaths and the causes thereof were obtained from the Danish National Board of Health. Cause of death was defined according to the following ICD codes for the immediate cause of death: COPD deaths 490-492 (ICD-8) or J40-J44 (ICD-10); respiratory deaths 460-519 (ICD-8) or J00-J99 (ICD-10), and cardiovascular deaths 390-458 (ICD-8) or I00I99 (ICD-10).

\section{Statistical analysis}

Kaplan-Meier curves and log rank tests of both COPD admission and mortality were performed after stratifying by levels of regular physical activity. In multivariate analysis, physical activity categories were a priori combined into "very low" and "low, moderate or high" levels according to the results of a previous study. ${ }^{6}$

For the study of the association between physical activity and COPD admission, the use of Poisson regression ${ }^{26}$ was ruled out because of the presence of overdispersion in our data and a high proportion of subjects not experiencing hospital admission. Instead, zero-inflated negative binomial regression with the number of COPD admissions as the outcome was used since it takes into account individuals more prone to repeated admission and provides more conservative confidence intervals and p values. ${ }^{27}$ In addition, Cox proportional hazards regression, modelling time from recruitment to first event, was used with COPD admission and mortality (all-cause, respiratory and cardiovascular) as the outcomes, checking the proportionality of multivariate models.

Among the variables detailed above, those considered as potential confounders of the association between physical activity and COPD admission or mortality were tested and were maintained in the final multivariate models if they were independently associated both with the outcome and exposure $(p<0.05)$ or if they modified the risk ratio estimate for any of the remaining covariates ( $\geqslant 5 \%$ change).$^{28}$ Final models were built keeping the most parsimonious model that still explains the data.

The final multivariate models for both COPD admission and mortality were stratified according to sex, age, COPD severity, and history of ischaemic heart disease. If differences in the risk estimate were found, interaction terms among variables where effect modification was plausible were tested for. For the sensitivity analyses, the final models for admission and mortality were run excluding subjects with self-reported asthma, those who had never smoked, and those less than 40 years of age. The analysis was performed using Stata release 8.0 (StataCorp, College Station, TX, USA). 
Table 1 Baseline characteristics of 2386 COPD subjects recruited from the general population in Copenhagen, Denmark

\begin{tabular}{|c|c|c|c|}
\hline & $\begin{array}{l}\text { All subjects* } \\
(n=2386)\end{array}$ & $\begin{array}{l}\text { Women } \\
(n=1100)\end{array}$ & $\begin{array}{l}\text { Men } \\
(n=1286)\end{array}$ \\
\hline Sex, n (\%) & & $1100(46.1)$ & $1286(53.9)$ \\
\hline Mean (SD) age (years) & $59.5(10.9)$ & $59.3(10.8)$ & $59.7(11.0)$ \\
\hline Education (mean (SD) years at school) & $8.3(1.9)$ & $8.3(1.8)$ & $8.4(2.0)$ \\
\hline Low income, $\mathrm{n}(\%) \dagger$ & $946(40.9)$ & $498(47.8)$ & $448(35.2)$ \\
\hline Mean (SD) BMI $\left(\mathrm{kg} / \mathrm{m}^{2}\right)$ & $24.9(4.2)$ & $24.2(4.5)$ & $25.6(3.8)$ \\
\hline Ischaemic heart disease, $n(\%) \neq$ & $634(26.6)$ & $249(22.6)$ & $385(29.9)$ \\
\hline Asthma, $\mathrm{n}(\%) \ddagger$ & $268(11.8)$ & $131(12.5)$ & $137(11.3)$ \\
\hline \multicolumn{4}{|l|}{ Dyspnoea, $\mathrm{n}(\%) \ddagger$} \\
\hline O (no dyspnoea) & $978(41.1)$ & $421(38.5)$ & $557(43.4)$ \\
\hline 1 (dyspnoea in effort) & $841(35.4)$ & $410(37.5)$ & $431(33.6)$ \\
\hline 2 (dyspnoea walking) & $240(10.1)$ & $119(10.9)$ & $121(9.4)$ \\
\hline 3 (dyspnoea at rest) & $318(13.4)$ & $144(13.1)$ & $174(13.6)$ \\
\hline Sputum, $\mathrm{n}(\%) \%$ & $939(39.4)$ & 381 (34.7) & $558(43.5)$ \\
\hline \multicolumn{4}{|l|}{ Smoking, $n(\%)$} \\
\hline Never & $230(9.7)$ & $174(15.9)$ & $56(4.3)$ \\
\hline Ex & 459 (19.3) & $184(16.8)$ & $275(21.4)$ \\
\hline Current & $1692(71.0)$ & $737(67.3)$ & $955(74.3)$ \\
\hline \multicolumn{4}{|l|}{ COPD severity (GOLD stages), n (\%)§ } \\
\hline I: Mild $\left(\mathrm{FEV}_{1} \geqslant 80 \%\right)$ & $833(35.1)$ & $363(33.1)$ & $470(36.7)$ \\
\hline II: Moderate (FEV $<80 \%$ and $\geqslant 50 \%$ ) & 1095 (46.1) & $521(47.6)$ & $574(44.8)$ \\
\hline III: Severe $\left(\mathrm{FEV}_{1}<50 \%\right.$ and $\left.\geqslant 30 \%\right)$ & 354 (14.9) & $166(15.2)$ & $188(14.7)$ \\
\hline IV: Very severe $\left(\mathrm{FEV}_{1}<30 \%\right)$ & $94(3.9)$ & $45(4.1)$ & $49(3.8)$ \\
\hline $\begin{array}{l}\text { Any medical visit to any doctor in previous } \\
\text { year, } n(\%)^{* *}\end{array}$ & $1871(78.8)$ & 911 (83.2) & $960(74.9)$ \\
\hline \multicolumn{4}{|c|}{$\begin{array}{l}\text { *The numbers do not always add up to } 2386 \text { as some values are missing for certain variables: } 11 \text { in education, } 5 \text { in } \\
\text { cohabitation, } 72 \text { in income, } 12 \text { in BMI, } 117 \text { in asthma, } 9 \text { in dyspnoea, } 5 \text { in sputum, } 5 \text { in smoking, } 10 \text { in lung } \\
\text { function, and } 10 \text { in visits to doctors. } \\
\text { tlow household income was defined as income lower than } 4000 \text { Danish kroner per month. } \\
\text { flschaemic heart disease and asthma were self-reported and obtained from medical records. Dyspnoea was self- } \\
\text { reported and categorised according to the Modified British Medical Research Council questionnaire. } \\
\text { - Sputum was considered present if subjects answered positively to the question "Do you usually bring up phlegm } \\
\text { from your chest in the morning or during the day?". } \\
\text { \$COPD severity was classified according to GOLD stages. } \\
\text { **Any medical visit to any doctor in previous year includes visits to the general practitioner, specialist, emergency } \\
\text { room or private doctor. }\end{array}$} \\
\hline
\end{tabular}

Table 2 Regular physical activity in 2386* COPD subjects recruited from the general population in Copenhagen, Denmark according to COPD severity (GOLD stages)

\begin{tabular}{|c|c|c|c|c|c|c|}
\hline & $\begin{array}{l}\text { All subjects } \\
(n=2386)\end{array}$ & $\begin{array}{l}\text { GOLD I: } \\
\text { Mild } \\
(n=833)\end{array}$ & $\begin{array}{l}\text { GOLD II: } \\
\text { Moderate } \\
\text { ( } \mathrm{n}=1095)\end{array}$ & $\begin{array}{l}\text { GOLD III: } \\
\text { Severe } \\
(n=354)\end{array}$ & $\begin{array}{l}\text { GOLD IV: } \\
\text { Very severe } \\
(n=94)\end{array}$ & $\begin{array}{l}\text { p value } \\
\left(\chi^{2} \text { test }\right)\end{array}$ \\
\hline \multicolumn{7}{|l|}{ Physical activity at work } \\
\hline Mainly sitting & $824(40.0)$ & $280(38.7)$ & $365(37.9)$ & $129(43.7)$ & $44(61.1)$ & \multirow{4}{*}{0.003} \\
\hline Sitting and standing & $763(37.0)$ & $254(35.1)$ & $376(39.0)$ & $111(37.6)$ & $20(27.8)$ & \\
\hline Walking \& lifting & $392(19.0)$ & $156(21.6)$ & $182(18.9)$ & $48(16.3)$ & $6(8.3)$ & \\
\hline Heary activity & $83(4.0)$ & $33(4.6)$ & $41(4.2)$ & $7(2.4)$ & $2(2.8)$ & \\
\hline \multicolumn{7}{|l|}{ Physical activity during leisure time } \\
\hline Light activity $<2 \mathrm{~h} /$ week and no heavy activity & $540(22.7)$ & $123(14.8)$ & $246(22.6)$ & $124(35.2)$ & $42(45.2)$ & \multirow[t]{3}{*}{$<0.001$} \\
\hline Light activity 2-4h/week and no heavy activity & $1073(45.2)$ & $385(46.4)$ & $506(46.4)$ & $143(40.6)$ & $37(39.8)$ & \\
\hline $\begin{array}{l}\text { Light activity }>4 \mathrm{~h} / \text { week and/or heavy activity } \\
<4 \mathrm{~h} / \text { week }\end{array}$ & $713(30.0)$ & $296(35.7)$ & $318(29.2)$ & $82(23.3)$ & $14(15.0)$ & \\
\hline Heavy activity $>4 \mathrm{~h} /$ week & $49(2.1)$ & $26(3.1)$ & $20(1.8)$ & $3(0.9)$ & $0(0)$ & \\
\hline Jogging & $39(1.6)$ & $20(2.4)$ & $17(1.6)$ & $2(0.6)$ & $0(0)$ & 0.068 \\
\hline \multicolumn{7}{|l|}{ Cycling winter (hours/week) } \\
\hline No & 1839 (77.5) & $582(70.4)$ & $865(79.4)$ & $299(84.9)$ & $83(89.2)$ & \multirow{5}{*}{$<0.001$} \\
\hline$<0.5$ & $224(9.5)$ & 108 (13.1) & $85(7.8)$ & $25(7.1)$ & $6(6.5)$ & \\
\hline $0.5-1$ & $180(7.6)$ & $79(9.5)$ & $79(7.3)$ & $19(5.4)$ & $3(3.2)$ & \\
\hline $1-2$ & $97(4.1)$ & $41(4.9)$ & $49(4.5)$ & $6(1.7)$ & $1(1.1)$ & \\
\hline$>2$ & $31(1.3)$ & $17(2.1)$ & $11(1.0)$ & $3(0.9)$ & $0(0)$ & \\
\hline \multicolumn{7}{|l|}{ Cycling summer (hours/week) } \\
\hline No & $1481(62.5)$ & $429(51.9)$ & 705 (64.7) & $260(74.0)$ & $78(84.8)$ & \multirow[t]{5}{*}{$<0.001$} \\
\hline$<0.5$ & $273(11.5)$ & $124(15.0)$ & $114(10.4)$ & $29(8.2)$ & $6(6.5)$ & \\
\hline $0.5-1$ & $291(12.3)$ & $136(16.4)$ & $122(11.2)$ & $29(8.2)$ & $3(3.2)$ & \\
\hline $1-2$ & 195 (8.2) & $86(10.4)$ & $90(8.3)$ & $17(4.8)$ & $2(2.2)$ & \\
\hline$>2$ & $131(5.5)$ & $52(6.3)$ & $59(5.4)$ & $17(4.8)$ & $3(3.3)$ & \\
\hline \multicolumn{7}{|l|}{ Physical activity summary score } \\
\hline Very low & $219(9.2)$ & $45(5.4)$ & $97(8.9)$ & $54(15.3)$ & $20(21.5)$ & \multirow[t]{4}{*}{$<0.001$} \\
\hline Low & 294 (12.4) & $69(8.3)$ & $138(12.7)$ & 65 (18.5) & $20(21.5)$ & \\
\hline Moderate & $1089(45.8)$ & $389(46.9)$ & $511(46.9)$ & $148(42)$ & $39(41.9)$ & \\
\hline High & $773(32.6)$ & $327(39.4)$ & $344(31.5)$ & 85 (24.2) & $14(15.1)$ & \\
\hline
\end{tabular}

Values are presented as $n(\%)$.

${ }^{*}$ The numbers do not always add up to 2386 as some values are missing for certain variables: 324 in physical activity at work, 11 in physical activity during leisure time, 8 in jogging, 15 in cycling in winter, 15 in cycling in summer, and 10 in lung function (GOLD stage). 

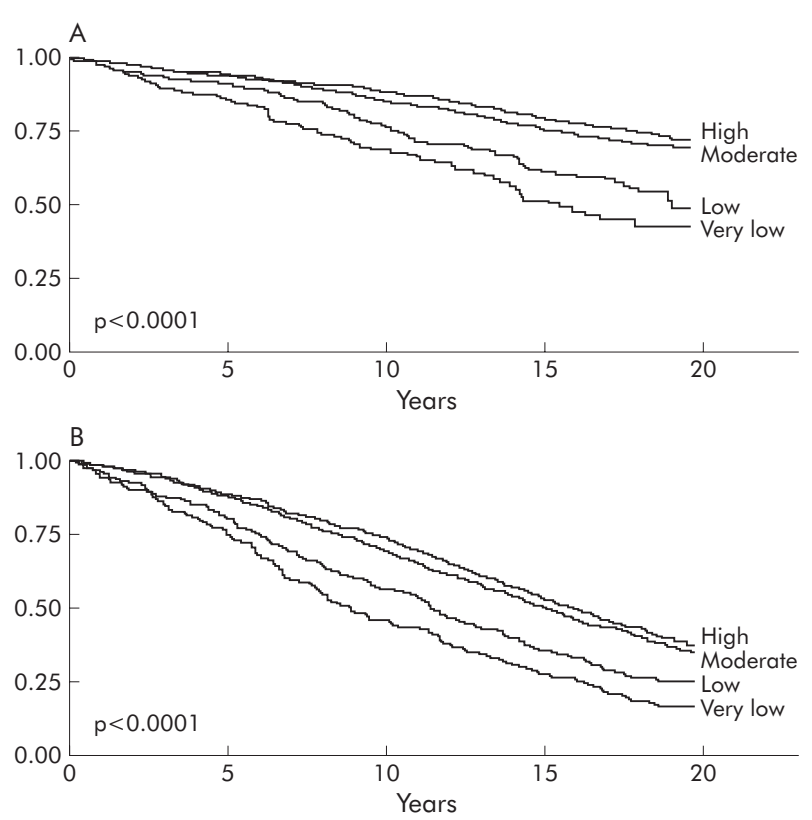

Figure 1 (A) Kaplan-Meier curve of time to first COPD admission during follow up according to level of regular physical activity. (B) Kaplan-Meier curve of time to death (all-cause mortality) according to level of regular physical activity.

\section{RESULTS}

Description of sample and events (COPD admission, death) during follow up

A total of 2386 subjects with COPD were included in the study. At baseline half were men, mean age was 60 years, mean body mass index $24.9 \mathrm{~kg} / \mathrm{m}^{2}, 12 \%$ reported having suffered asthma at some time, and $71 \%$ were current smokers (table 1).

Classification of severity according to GOLD stages showed a high prevalence of mild (35\%) and moderate (46\%) COPD. Very low, low, moderate, and high levels of physical activity were reported by $9 \%, 12 \%, 46 \%$, and $33 \%$ of subjects, respectively (table 2 ). Subjects with more severe COPD had lower levels of physical activity.

During the mean (SD) follow up period of 12.0 (5.9) years, $22 \%$ of participants had at least one hospital admission due to COPD (median 3, interquartile range $1-5$ for those with an admission). As expected, the subjects admitted to hospital were older, had a higher proportion of cardiovascular disease and asthma, performed lower levels of physical activity, and suffered more severe COPD. The time to first COPD admission during follow up was shorter for the subjects with lower levels of physical activity (fig lA).

During the follow up period 1425 subjects $(60 \%)$ died. Death from respiratory and cardiovascular diseases constituted $18 \%$ and $32 \%$ of all deaths, respectively, with $14 \%$ of deaths due to COPD. The subjects who died were older, had a higher proportion of cardiovascular disease and diabetes, performed lower levels of physical activity, and also suffered more severe COPD. The time to death was shorter in subjects with lower levels of physical activity (fig lB).

\section{Association between physical activity and both COPD hospital admission and mortality}

In the multivariate negative binomial model with the number of COPD admissions as the outcome, subjects who reported low, moderate, or high levels of physical activity had a lower risk of a COPD admission than those reporting a very low level of physical activity, after adjusting for confounders (incidence rate ratio (IRR) $0.72,95 \%$ CI 0.53 to 0.97 , $\mathrm{p}=0.033$; table 3 ). Using the time to first COPD admission as the outcome in a multivariate Cox regression model yielded very similar results (hazard ratio (HR) 0.76 , 95\% CI 0.58 to $0.99, \mathrm{p}=0.039$ ).

After adjusting for all relevant confounders, subjects who reported low, moderate or high physical activity had a lower risk of all-cause mortality (HR 0.76 , 95\% CI 0.65 to 0.90 , $\mathrm{p}=0.001$ ), death from respiratory causes (HR $0.70,0.48$ to $1.02, \mathrm{p}=0.060$ ), and death from cardiovascular causes (HR $0.77,0.58$ to $1.02, p=0.065)$ than the group with very low physical activity (table 4 ).

After stratification for sex, age, COPD stage, and history of ischaemic heart disease, subjects who reported low, moderate or high level of physical activity had a reduced risk of both hospital admission for COPD and death due to any cause in all subgroups of subjects than those with a very low level of physical activity, although statistical significance was lost in many models, most likely due to a reduction in statistical power (data not shown, available from the authors).

Sensitivity analyses yielded very similar results. After excluding the subjects who reported having suffered asthma at some time, the adjusted IRR of a COPD admission for those with low, moderate or high physical activity compared with those reporting very low physical activity was 0.72 (95\% CI 0.50 to $1.04, \mathrm{p}=0.082$ ); correspondingly, the adjusted HR for all-cause mortality was 0.76 (95\% CI 0.63 to 0.91 ,

\begin{tabular}{|c|c|c|c|c|c|}
\hline & $\mathbf{n}^{*}$ & $\begin{array}{l}\text { Crude IRR } \\
(95 \% \mathrm{Cl})\end{array}$ & p value & $\begin{array}{l}\text { Adjustedt IRR } \\
(95 \% \mathrm{Cl})\end{array}$ & $\mathrm{p}$ value \\
\hline \multicolumn{6}{|c|}{ Physical activity (combined) } \\
\hline Very low & 219 & 1 & & 1 & \\
\hline Low/moderate/high & 2155 & $0.63(0.46$ to 0.86$)$ & 0.004 & 0.72 (0.53 to 0.97$)$ & 0.033 \\
\hline \multicolumn{6}{|c|}{ Physical activity (categories) } \\
\hline Very low & 219 & 1 & & 1 & \\
\hline Low & 294 & $0.73(0.49$ to 1.08$)$ & 0.113 & 0.77 (0.53 to 1.14$)$ & 0.192 \\
\hline Moderate & 1089 & $0.63(0.45$ to 0.88$)$ & 0.006 & $0.68(0.49$ to 0.93$)$ & 0.018 \\
\hline High & 772 & $0.57(0.40$ to 0.82$)$ & 0.002 & $0.76(0.53$ to 1.08$)$ & 0.121 \\
\hline $\mathrm{p}$ for linear trend & & & 0.002 & & 0.104 \\
\hline
\end{tabular}

IRR, incident rate ratio; $\mathrm{Cl}$, confidence interval.

*The number of subjects may be lower in the multivariate models as some values are missing for certain variables (see tables 1 and 2). One subject was excluded from the zero-inflated negative binomial regression model for recording 65 COPD admissions during follow up (outlier value).

TMultivariate model adjusted for sputum and $\mathrm{FEV}_{1}$ in the count component, and for age, ischaemic heart disease, smoking habit, sputum, visits to doctor, and $\mathrm{FEV}_{1}$ in the zero-inflated component of the zero-inflated negative binomial regression. 


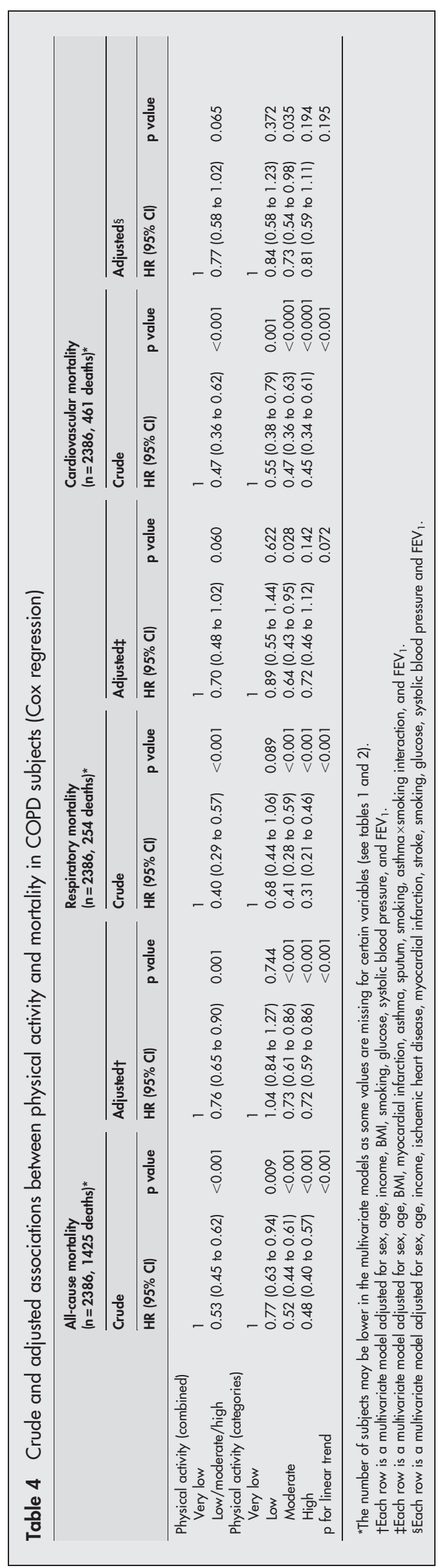

$\mathrm{p}=0.003)$. After excluding never smokers, the adjusted IRR of a COPD admission was 0.70 (95\% CI 0.52 to 0.96 , $\mathrm{p}=0.026)$ and the adjusted HR of all-cause mortality was 0.76 ( $95 \%$ CI 0.64 to $0.90, p=0.001)$. After excluding subjects less than 40 years of age, the adjusted IRR of a COPD admission was $0.72(95 \%$ CI 0.53 to $0.98, p=0.037)$ and the adjusted HR of all-cause mortality was 0.77 (95\% CI 0.65 to $0.91, \mathrm{p}=0.002$ )

Given the results of the bivariate analysis (figs 1A and B), all analyses were run taking together those reporting a very low or low level of physical activity $(n=513)$ as the reference category, providing an adjusted IRR for a COPD admission of 0.80 ( $95 \%$ CI 0.64 to $1.01, p=0.065$ ) and the following adjusted HRs for mortality: all-cause 0.71 (95\% CI 0.63 to $0.80, \mathrm{p}<0.001$ ), respiratory causes 0.71 (95\% CI 0.53 to 0.95 , $\mathrm{p}=0.021)$, and cardiovascular causes $0.82(95 \%$ CI 0.66 to $1.03, \mathrm{p}=0.084$ ).

\section{DISCUSSION}

This 20 year follow up study of 2386 subjects with COPD shows that, for these subjects, a level of physical activity equivalent to walking or cycling 2 hours/week or more was associated with a $30-40 \%$ reduction in the risk of both hospital admission due to COPD and respiratory mortality. This is the first population-based cohort study showing that a relatively small amount of physical activity may have important beneficial effects on the course of COPD. To date, only the British guidelines for $\mathrm{COPD}^{8}$ advise that COPD patients should be encouraged to exercise (page S12), a recommendation that so far is not evidence-based. The present results provide robust evidence in favour of this recommendation and support for its consideration in future COPD guidelines.

The results of this study are highly consistent with our previous observation of a reduction in COPD hospital admissions among patients with COPD recruited from tertiary hospitals in Barcelona who reported a level of physical activity equivalent to walking 1 hour daily. ${ }^{6}$ The important environmental and climatic differences between Copenhagen and Barcelona are likely to result in different patterns of physical activity, reinforcing the external validity of the reported associations.

Some respiratory rehabilitation trials have shown a reduced risk of COPD admission. ${ }^{29-31}$ Since the majority of respiratory rehabilitation programs include a component of exercise training, it could be considered that the effects reported in our study and those reported in respiratory rehabilitation studies are consistent. However, respiratory rehabilitation also incorporates other pharmacological and non-pharmacological interventions and the effect of exercise training cannot be isolated. ${ }^{32}$ Whereas respiratory rehabilitation should be considered in specific COPD patients, our results suggest the convenience of incorporating the advice of increasing or maintaining a moderate level of physical activity at any medical encounter with patients with COPD of all stages. Further interventional studies should test the efficacy and effectiveness of physical activity advice in COPD subjects.

The mechanisms underlying the potential beneficial effects of regular physical activity in COPD are not known, although some evidence regarding muscle function, exercise capacity, and inflammation may give support to its biological plausibility. Physical activity improves peripheral muscle function,,$^{33}$ and this has been related to reduced use of health services in patients with COPD. ${ }^{34}$ At the cellular level, exercise training improves the bioenergetics of skeletal muscle in COPD patients ${ }^{35}$ which, through a reduction in lactate production during exercise, could reduce symptoms. ${ }^{36}$ On the other hand, exercise capacity has been associated with a 
lower risk of hospital admission for COPD exacerbation ${ }^{37}$ and a lower risk of mortality ${ }^{38}{ }^{39}$ in COPD cohorts. The extent to which exercise capacity in COPD patients is influenced by regular physical activity and vice versa is not known, although a cross sectional association between the two has been reported. ${ }^{40}$ Finally, important anti-inflammatory and anti-oxidant effects have been reported both in healthy subjects exposed to moderate levels of exercise ${ }^{41} 42$ and in COPD patients participating in rehabilitation programs. ${ }^{43} 44$

As with any observational study, ours may be affected by several limitations. Since losses to follow up are the main cause of selection bias in longitudinal studies ${ }^{45}$ and only four subjects $(0.2 \%)$ were lost to follow up in our study, it is unlikely that selection will have biased the estimates of the effects of physical activity in the course of COPD. It is most likely that we will have measured regular physical activity with a degree of non-differential misclassification, both because of the inherent limited validity of the questionnaire and the omission of changes in physical activity during follow up. In either case, the resulting effect was most probably a reduced estimate of the effects of physical activity. ${ }^{22}{ }^{45}$ Given that the present study was not specifically designed to examine the effects of physical activity, direct measures were not available but should be considered in future studies. Our study was designed to test the hypothesis that physical activity may reduce the risk of COPD admission or respiratory related death in COPD patients, and consequently our study population included only patients with COPD. The inclusion of a reference group without COPD would not have been appropriate since control subjects exposed to physical activity would not have had the opportunity of experiencing the expected effects.

We considered the possibility of dyspnoea acting as a confounder since it was not included in the final models, even though its presence was associated with both physical activity and the outcomes. The inclusion of dyspnoea in the regression models did not change the magnitude of the associations between physical activity and COPD admission or mortality (IRR for COPD admission 0.82 , 95\% CI 0.60 to 1.11; HR for mortality $0.80,95 \%$ CI 0.68 to 0.95 ), with the magnitude of the potential confounding effect being virtually null. ${ }^{45}$ In addition, since dyspnoea could also be an intermediate variable between reduced levels of physical activity and an increased risk of admission or mortality, and as dyspnoea was correlated with physical activity, its inclusion in our multivariate models was avoided. We are currently exploring the applicability of marginal structural models to disentangle the individual effects of physical activity and dyspnoea. ${ }^{46}$

It should also be considered whether the group of subjects who reported very low physical activity represent a specific group with an unhealthy lifestyle, which could partially account for an increased risk of COPD admission and mortality. However, multivariate models already included smoking and income as covariates, and the inclusion of alcohol consumption or other sociodemographic factors (education, marital status or cohabitation) did not change the estimates for physical activity (results available from the authors). Other markers of lifestyle such as diet were not available but should be explored in future studies.

The lack of a linear dose-response relationship between levels of physical activity and admission to hospital or mortality may cast some doubts on the observed estimates. However, no clear dose-response relationship between physical activity and health related outcomes has been reported for hypertension, obesity, cancer, osteoporosis, quality of life, depression and anxiety, among other disorders. ${ }^{47}$ Whether the lack of a clear dose-response association is due to the real lack of a dose-response relationship, a lack of sensitivity in determining the dose of physical activity, or uncontrolled confounders is generally not known. ${ }^{47}$ However, because the kind of dose-response relationship is important for public health, we recommend that this issue should be addressed in further research by using more accurate measures of physical activity including frequency, duration, and intensity. ${ }^{47}$

In summary, our results provide robust evidence that the performance of regular physical activity by patients with COPD is associated with an important reduction in the risk of both admission to hospital with COPD and all-cause and respiratory mortality. The magnitude of this effect and the fact that the type of physical activity required to achieve it can be easily recommended without the need for additional training or specialised supervision make these findings particularly promising. Our results provide evidence that future COPD guidelines should consider the recommendation that COPD patients be encouraged to maintain or increase their levels of regular physical activity. Given that COPD is a chronic disease associated with a high socioeconomic burden and health consequences, such a measure is likely to result in a relevant public health benefit.

\section{ACKNOWLEDGEMENTS}

The authors thank Dr Jorgen Vestbo for his stimuli and advice on commencing the study.

\section{Authors' affiliations}

J Garcia-Aymerich, M Benet, J M Antó, Respiratory and Environmental Health Research Unit, Institut Municipal d'Investigació Mèdica (IMIM), Barcelona, Spain

P Lange, P Schnohr, Copenhagen City Heart Study, Epidemiological Research Unit, Bispebjerg University Hospital, Copenhagen, Denmark P Lange, Department of Cardiology and Respiratory Diseases, Hvidovre University Hospital, Denmark

J M Antó, Department of Experimental and Health Sciences, Universitat Pompeu Fabra, Barcelona, Spain

Funding: Supported in part by grants from the Generalitat de CatalunyaDURSI 2001/SGR/00406. JG-A and MB were respectively funded by the Red RESPIRA Network (RTIC C03/11) and the Red RCESP Network (RTIC C03/09), from the Instituto de Salud Carlos III. The Copenhagen City Heart Study was supported by grants from The Danish Heart Foundation, The Danish Lung Association and Danish Medical Research Council. No part of the research presented has been funded by tobacco industry sources. The sources of funding had no involvement in study design and conduct; collection, management, analysis or interpretation of data; and preparation, review, or approval of the manuscript.

\section{Competing interests: none.}

JG-A, PL, PS, and JMA participated in the design of the study; PL and PS coordinated data collection in Copenhagen; JG-A, PL, MB, and JMA performed the statistical analysis and interpreted the results; JG-A prepared the first draft of the paper; and all the authors contributed to the writing of paper. JG-A had full access to all of the data in the study and takes responsibility for the integrity of the data and the accuracy of the data analysis.

\section{REFERENCES}

1 Mannino DM, Homa DM, Akinbami $\sqcup$, et al. Chronic obstructive pulmonary disease surveillance - United States, 1971-2000. MMWR 2002:51:1-16.

2 Murray CJL, Lopez AD. Alternative projections of mortality and disability by cause 1990-2020: Global Burden of Disease Study. Lancet 1997;349:1498-504.

3 Pawels R, Buist SA, Calverley P, et al. Global strategy for the diagnosis, management and prevention of chronic obstructive pulmonary disease. NHLBI/WHO Global Initiative for Chronic Obstructive Lung Disease (GOLD). Workshop summary. Am J Respir Crit Care Med 2001;163:1256-76.

4 American Thoracic Society and European Respiratory Society. Standards for the diagnosis and treatment of patients with chronic obstructive pulmonary disease. Available at http://www.thoracic.org/copd/copdpdf.asp.

5 Sullivan SD, Ramsey SD, Lee TA. The economic burden of COPD. Chest 2000;117:5-9S. 
6 Garcia-Aymerich J, Farrero E, Felez MA, et al. Risk factors of readmission to hospital for a COPD exacerbation: a prospective study. Thorax 2003;58:100-5.

7 Morgan MD. Preventing hospital admissions for COPD: role of physical activity (editorial). Thorax 2003;58:95-6.

8 COPD Guidelines Group of the Standards of Care Commitee of the BTS. BTS guidelines for the management of chronic obstructive pulmonary disease. Thorax 1997;52(Suppl 5):S1-28.

9 Pate RR, Pratt M, Blair SN, et al. Physical activity and public health. A recommendation from the Centers for Disease Control and Prevention and the American College of Sports Medicine. JAMA 1995;273:402-7.

10 Di Loreto C, Fanelli C, Lucidi P, et al. Make your diabetic patients walk: longterm impact of different amounts of physical activity on type 2 diabetes. Diabetes Care 2005;28:1295-302.

11 Schmitz KH, Holtzman J, Courneya KS, et al. Controlled physical activity trials in cancer survivors: a systematic review and meta-analysis. Cancer Epidemiol Biomarkers Prev 2005; 14:1588-95.

12 Brown JK, Byers T, Doyle C, et al. Nutrition and physical activity during and after cancer treatment: an American Cancer Society guide for informed choices. CA Cancer J Clin 2003;53:268-91.

13 Holmes MD, Chen WY, Feskanich D, et al. Physical activity and survival after breast cancer diagnosis. JAMA 2005;293:2479-86.

14 Vestbo J, Prescott E, Lange P. Association of chronic mucus hypersecretion with $\mathrm{FEV}_{1}$ decline and chronic obstructive pulmonary disease morbidity. Am J Respir Crit Care Med 1996;153:1530-5.

15 Vestbo J, Hansen EF. Airway hyperresponsiveness and COPD mortality. Thorax 2001;56:11-4.

16 Landbo $C$, Prescott E, Lange $P$, et al. Prognostic value of nutritional status in chronic obstructive pulmonary disease. Am J Respir Crit Care Med 1999; 160:1856-61.

17 Appleyard M, Hansen A, Schnohr P, et al. The Copenhagen City Heart Study: a book of tables with data from the first examination (1976-78) and five years follow-up (1981-1983). Scand J Soc Med 1989;170(Suppl 41):1-160.

18 Schnohr P, Jensen G, Lange P, et al. The Copenhagen City Heart Study. Tables with data from the third examination 1991-1994. Eur Respir J 2001;3(Suppl H): 1-83.

19 Eltayara L, Becklake MR, Volta CA, et al. Relationship between chronic dyspnea and expiratory flow limitation in patients with chronic obstructive pulmonary disease. Am J Respir Crit Care Med 1996;154:1726-34.

20 Saltin B, Grimby G. Physiological analysis of middle-aged and old former athletes: comparison with still active athletes of the same ages. Circulation 1968:38:1104-15.

21 Saltin B. Physiological effects of physical conditioning. In: Hansen AT, Schnohr P, Rose G, eds. Ischaemic heart disease: the strategy of postponement. Chicago, IL: Year Book Medical Publishers, 1977:104-15.

22 Andersen LB. Relative risk of mortality in the physically inactive is underestimated because of real changes in exposure level during follow-up. Am J Epidemiol 2004; 160:189-95.

23 Lissner L, Potischman N, Troiano R, et al. Recall of physical activity in the distant past: the 32-year follow-up of the Prospective Population Study of Women in Goteborg, Sweden. Am J Epidemiol 2004;159:304-7.

24 Schnohr $\mathbf{P}$, Scharling $\mathrm{H}$, Jensen JS. Changes in leisure-time physical activity and risk of death: an observational study of 7,000 men and women. Am J Epidemiol 2003;158:639-44.

25 Lange $P$, Nyboe J, Jensen $G$, et al. Ventilatory function impairment and risk of cardiovascular death and of fatal or non-fatal myocardial infarction. Eur Respir J 1991;4:1080-7.
26 Sturmer T, Glynn RJ, Kliebsch U, et al. Analytic strategies for recurrent events in epidemiologic studies: background and application to hospitalization risk in the elderly. J Clin Epidemiol 2000;53:57-64.

27 Glynn RJ, Buring JE. Ways of measuring rates of recurrent events. BMJ 1996;312:364-7.

28 Rothman KJ, Greenland S. Modern epidemiology. Philadelphia: LippincottRaven, 1998.

29 Guell R, Casan P, Belda J, et al. Long-term effects of outpatient rehabilitation of COPD: a randomized trial. Chest 2000;117:976-83.

30 Griffiths TL, Burr ML, Campbell IA, et al. Results at 1 year of outpatient multidisciplinary pulmonary rehabilitation: a randomised controlled trial. Lancet 2000;355:362-8.

31 Puhan MA, Scharplatz M, Troosters $T$, et al. Respiratory rehabilitation after acute exacerbation of COPD may reduce risk for readmission and mortalitya systematic review. Respir Res 2005;6:54.

32 American Thoracic Society. Pulmonary rehabilitation: official statement of the American Thoracic Society. Am J Respir Crit Care Med 1999;159:1666-82.

33 Casaburi R. Skeletal muscle dysfunction in chronic obstructive pulmonary disease (review). Med Sci Sports Exerc 2001;33(7 Suppl):S662-70.

34 Decramer M, Gosselink R, Troosters T, et al. Muscle weakness is related to utilization of health care resources in COPD patients. Eur Respir $J$ 1997:10:417-23.

35 Sala E, Roca J, Marrades RM, et al. Effects of endurance training on skeletal muscle bioenergetics in chronic obstructive pulmonary disease. Am J Respir Crit Care Med 1999;159:1726-34.

36 Casaburi R, Porszasz J, Burns MR, et al. Physiologic benefits of exercise training in rehabilitation of patients with severe chronic obstructive pulmonary disease. Am J Respir Crit Care Med 1997;155:1541-51

37 Kessler R, Faller M, Fourgaut $G$, et al. Predictive factors of hospitalization for acute exacerbation in a series of 64 patients with chronic obstructive pulmonary disease. Am J Respir Crit Care Med 1999;159:158-64.

38 Pinto-Plata VM, Cote C, Cabral H, et al. The 6-min walk distance: change over time and value as a predictor of survival in severe COPD. Eur Respir J 2004;23:28-33.

39 Oga T, Nishimura K, Tsukino M, et al. Analysis of the factors related to mortality in chronic obstructive pulmonary disease: role of exercise capacity and health status. Am J Respir Crit Care Med 2003;167:544-9.

40 Pitta F, Troosters T, Spruit MA, et al. Characteristics of physical activities in daily life in chronic obstructive pulmonary disease. Am J Respir Crit Care Med 2005;171:972-7.

41 Das UN. Anti-inflammatory nature of exercise. Nutrition 2004;20:323-6.

42 Ramel A, Wagner KH, Elmadfa I. Plasma antioxidants and lipid oxidation after submaximal resistance exercise in men. Eur J Nutr 2004;43:2-6.

43 Rabinovich RA, Ardite E, Troosters T, et al. Reduced muscle redox capacity after endurance training in patients with chronic obstructive pulmonary disease. Am J Respir Crit Care Med 2001;164:1114-8.

44 Rabinovich RA, Figueras $M$, Ardite $E$, et al. Increased tumour necrosis factoralpha plasma levels during moderate-intensity exercise in COPD patients. Eur Respir J 2003;21:789-94.

45 Szklo M, Nieto J. Epidemiology beyond the basics. Gaithersburg: Aspen Publishers Inc, 2000

46 Robins JM, Hernan MA, Brumback B. Marginal structural models and causal inference in epidemiology. Epidemiology 2000;1 1:550-60.

47 Kesaniemi YK, Danforth E Jr, Jensen MD, et al. Dose-response issues concerning physical activity and health: an evidence-based symposium. Med Sci Sports Exerc 2001;33(6 Suppl):S351-8 